\title{
КЛИНИЧЕСКИЙ СЛУЧАЙ СИНДРОМАЛЬНОЙ ЗАДЕРЖКИ РОСТА В СОСТАВЕ СИНДРОМА ШЕЙТХАУЭРА-МАРИ-СЕНТОНА (ЧЕРЕПНО-КЛЮЧИЧНАЯ ДИСПЛАЗИЯ)
}

\author{
Еникеева С.P., Болмасова А.В., Гичкина Т.С., Меликян М.А.
}

ФГБУ «Национальный медицинский исследовательский центр эндокринологии» Минздрава России

\begin{abstract}
Введение. Синдром Шейтхауэра-Мари-Селтона (черепно-ключичная дисплазия) является редким аутосомно-доминантным заболеванием, вызванным мутациями гена $R U N X 2$. Частота встречаемости синдрома составляет 1:1000000, равная для мужчин и женщин. К его типичным проявлениям относят низкий рост, гипоплазию верхней челюсти, гипертелоризм, позднее закрытие родничков черепа, избыточную подвижность плечей (вследствие патологии ключиц).
\end{abstract}

Ген $R U N X 2$ необходим для формирования скелета, а именно для дифференцировки остеобластов в ходе как интрамембранозного, так и энхондрального окостенения. Будучи транскрипционным фактором, он регулирует экспрессию генов костного матрикса, включающих коллаген I, остеокальцин, костный сиалопротеин и остеопонин. Локализован на длинном плече 6 хромосомы (6p21) и имеет 2 типа: тип 1 экспрессируется в Т-клетках, остеобластах и хондроцитах и способствует интрамембранозному типу окостенения; экспрессия типа 2 возрастает в процессе дифференцировки остеобластов и отвечает за энхондральное окостенение. Аутосомно-доминантные мутации гена приводят к нарушению закрытия родничков и черепных швов, брахицефалии, плоской переносице, скученности и увеличенному количеству зубов, задержке их прорезывания, гипо/аплазии ключиц - что составляет главные компоненты данного синдрома

Описание клинического случая. Пациент М, 8 лет, обратился в ФГБУ “НМИЦ эндокринологии” МЗ РФ первично с жалобами на отставание в росте. Из анамнеза известно, что с 1 года наблюдается неврологом по поводу черепно-ключичной дисплазии, установленной на основании клиникофенотипической картины (аплазия ключиц по данным рентгенографии, частичное отсутствие лобных, височных и теменных костей по данным МСКТ головы). Отставание в росте отмечает с рождения.

При осмотре выявлена умеренная задержка роста (рост 118,2 см; SDS роста -2,09) при нормальной массе тела (SDS ИМТ 1,69). Обращало на себя внимание конусовидная грудная клетка за счет узкого плечевого пояса, покатые плечи, возможность соприкасания плечами спереди грудины, брахицефалия, гипертелоризм. При пальпации отмечается наличие открытых швов и родничков черепа. Выявлена вальгусная деформация нижних конечностей, плоско-вальгусная деформация стоп. Также отмечалась деформация зубного ряда, потемнение эмали.

В гормональном профиле выявлен соответствующий возрасту и стадии полового развития уровень ИФР-1 (163,4 нг/мл), отставание костного возраста от паспортного (на 1,5 года от паспортного по атласу TW20). Конечный прогнозируемый рост с учетом костного возраста по Bayley-Pinneau 164,6 cM.

Для верификации диагноза проведено молекулярно-генетическое исследование гена $R U N X 2$ методом прямого секвенирования. В гене $R U N X 2$ (NM 001024630.4) в 8 интроне выявлена замена в сайте сплайсинга c.1088 -2A>G в гетерозиготном состоянии, патогенная, не описана.

Учитывая умеренную задержку роста, благоприятный ростовой прогноз, отсутствие данных о положительном эффекте ростстимулирующей терапии, принято решение воздержаться от проведения СТГ-стимуляционных проб в настоящее время. 
Заключение. Сочетание задержки роста, гипоплазии ключиц, наличие открытых родничков, а также стигмы лицевого скелета позволяют заподозрить данный синдром, что необходимо при определении дальнейшей тактики ведения пациентов, а именно планировании ростстимулирующей терапии и ортодонтического лечения. Данный случай иллюстрирует легкую степень задержки роста, что требует дальнейшего наблюдения и дает время для накопления сведений о возможностях ростстимулирующей терапии в рамках синдрома. 